\title{
Knowledge and Attitudes Concerning SARS-CoV-2 Among Healthcare Workers in Mirpur, Azad Jammu and Kashmir, Pakistan
}

\author{
Usman Waheed ${ }^{1 *}$, Ahmad Farooq ${ }^{2}$, Akhlaaq Wazeer ${ }^{3}$, Noor e Saba ${ }^{4}$, Zahida Qasim³, \\ Farooq Ahmed Noor $^{3}$, Naila Arif Cheema ${ }^{5}$ and Muhammad Arshad ${ }^{2}$ \\ ${ }^{1}$ Department of Pathology and Transfusion Medicine, Shaheed Zulfiqar Ali Bhutto Medical University, Islamabad, Pakistan \\ ${ }^{2}$ Department of Biological Sciences, International Islamic University, Islamabad, Pakistan \\ ${ }^{3}$ Department of Pathology and Transfusion Medicine, Divisional Headquarters Teaching Hospital, Mirpur, \\ Azad Jammu and Kashmir, Pakistan \\ ${ }^{4}$ Institute of Basic Medical Sciences, Khyber Medical University, Peshawar, Pakistan \\ ${ }^{5}$ Department of Biology, National University of Technology, Islamabad, Pakistan.
}

\begin{abstract}
Background: The healthcare workers are leading the fight against the coronavirus pandemic and are at great risk of acquiring the infection. The information on the knowledge and attitude of healthcare workers towards SARS-CoV-2 is useful to plan awareness and educational programs.
\end{abstract}

Aim: To assess the knowledge and attitude of healthcare workers towards SARS-CoV-2 in Mirpur, Azad Jammu and Kashmir, Pakistan.

Material and Methods: A cross-sectional study was performed during March and April 2020, on healthcare workers in a tertiary care divisional headquarters teaching hospital of Mirpur, Azad Jammu and Kashmir, Pakistan. A self-administered questionnaire was used to collect the data through a face to face approach. The data were organized and statistically analyzed through SPSS version 21.0 .

Results: A total of 520 healthcare workers were approached and 468 of them filled and returned the questionnaire, giving a response rate of $90.0 \%$. The age range of the participants was 18 to 59 years with a mean of $31.5 \pm 4.9$ years. The majority of respondents were males $(62.4 \%)$ and more than half of the participants had knowledge of the SARS-CoV-2 outbreak (62.1\%) and their main source of information was television (51.3\%). Overall, $60.6 \%$ had sufficient knowledge of the disease and $79.7 \%$ had a positive attitude towards SARS-CoV-2.

Conclusion: The outcomes of our study revealed that overall healthcare workers had an acceptable level of knowledge and a positive attitude towards the SARS-CoV-2 outbreak.

Keywords: SARS-CoV-2, outbreak, COVID-19, knowledge, attitude, healthcare workers.

\section{INTRODUCTION}

The ongoing pandemic of coronavirus disease 2019 (COVID-19) caused by SARS-CoV-2, emerged in the Chinese city of Wuhan last December. As of August 24, 2020, the disease has so far infected more than 23.4 million people killing an estimated 0.890 million people globally [1]. The WHO declared the SARS-CoV-2 outbreak a public health emergency of international concern in January and a pandemic in early March [2].

Pakistan has an international border with the People's Republic of China and took all necessary measures to limit the disease transmission in the country. However the first case of the disease was reported in the last week of February 2020, and since then the number has now crossed 0.293 million [3]. The earliest infected cases in Pakistan were primarily those traveling from Iran and Saudi Arabia. Later the transmission dynamics

*Corresponding Author: Usman Waheed, Ph.D., Department of Pathology and Transfusion Medicine, Shaheed Zulfiqar Ali Bhutto Medical University, Islamabad, Pakistan

Email: usman.waheed07@gmail.com; drusman.waheed1@gmail.com

Received: May 15, 2020; Revised: September 07, 2020; Accepted: September 22, 2020 DOI: https://doi.org/10.37184/lnjpc.2707-3521.2.4 changed and followed a local human-to-human transmission. Meanwhile, the Government of Pakistan enforced a 6-week lockdown to mitigate the SARS-CoV-2. With the advent of SARS-CoV-2 and the imposed lockdown to ensure social distancing, the psychological fallout of the pandemic continues to rise. The lockdown is taking a toll on mental health and the pandemic has reached its tentacles into just about every area of life at this point.

The healthcare industry is one of the most unsafe environments to work in as the workers including doctors, nurses, technicians, helpers, and waste handlers, are constantly exposed to serious hazards. In the current disaster pandemic, the healthcare workers are spearheading the fight against SARS-CoV-2. Considering the mode of transmission, these workers are at high risk for viral exposure which makes them highly vulnerable to acquire the occupational infection [4]. Studies with other viral outbreaks have shown that the frequency of viral agents in healthcare workers dealing with the patients, was up to $20.9 \%[5,6]$. Although the exact figures are not yet available, in some 
countries, up to $10 \%$ of healthcare workers are being infected by a coronavirus and many of them have died [7]. Only in China, more than 1,700 healthcare workers acquired the infection in the first two months [8]. So far, no vaccine and antiviral therapy are specifically recommended for SARS-CoV-2. Hence, applying preventive actions to reduce the transmission of the disease is of prime importance. However, the implementation of these precautionary measures depends solely on awareness and compliance among healthcare workers. A poor knowledge base was found to be supporting the rapid spread of the infection in hospital settings [9]. In the past, healthcare workers have been assessed in terms of their knowledge and attitude in similar viral outbreaks. The results showed a poor understanding of the disease and its dynamics [10-12].

This current study was performed to examine the knowledge and attitude of healthcare workers towards SARS-CoV-2 in a tertiary care hospital setting. The study findings will be useful to recommend remedial actions and necessary educational programs to improve awareness and attitudes among healthcare workers.

\section{MATERIAL AND METHODS}

This was a descriptive, cross-sectional study conducted at the Divisional Headquarters (DHQ) Teaching Hospital, Mirpur, Azad Jammu and Kashmir, Pakistan, during March and April 2020. The hospital is a divisional-level tertiary care facility catering to a population of 1.6 million from three districts including Mirpur, Kotli, and Bhimber. The daily OPD of the hospital is approximately 1,100 . The study was performed under the international guidelines of STROBE (Strengthening the Reporting for Observational Studies in Epidemiology) [13]. Ethical clearance of the study was granted by the Hospital Ethics Committee of DHQ Teaching Hospital, Mirpur (No. 8174/MS/2020).

The sample size was calculated based on the assumption that $50 \%$ percent of the people would have good knowledge of SARS-COV-2. Thus, with a precision of $5 \%$ and a $95 \%$ confidence interval, a minimum sample of 384 participants was required as estimated by using the online available calculator Open-Epi. The total number of healthcare workers in the hospital is 520 including clinicians, nurses, pharmacists, technicians, and support staff such as hospital waste handlers. All these workers were included in the study. The questionnaire was designed in English and was self-administered. The questionnaire was pre-tested in a population of 10 healthcare workers who were not part of the study to help determine whether the questionnaire is understandable. This practice yielded valuable comments from the 10 respondents and was used to adapt and further develop the questionnaire. The questionnaire was structured in a way to be anonymous and the data were kept confidential. A face to face approach was followed to gather the data from respondents.

The questionnaire was formulated, with some amendments, using the frequently asked questions from the CDC [14] and WHO [15] websites. The questionnaire was divided into three sections intended to collect information on (a) five questions related to demographic data and source of participant's knowledge on SARS-CoV-2; (b) 10 questions related to knowledge of study participants; and (c) seven questions regarding the attitude of participants towards SARS-CoV-2 in a yes or no format.

Regarding the scoring system, one point was given for the correct answer and zero points for an incorrect answer. The total knowledge score varied between 0 (with no correct answer) and 10 (for all correct answers), and a cut off level of $<7$ was evaluated as insufficient knowledge, and $\geq 7$ indicated sufficient knowledge. For the attitude portion of the questionnaire, one point was given for positive response, and an overall percentage of $70 \%$ was considered as a good attitude.

The data were collected, organized, and statistically evaluated by SPSS software (Statistical Program for Social Science version 21.0). Data were presented in the form of frequencies and percentages. Chi-square test was applied to find the association of participants' characteristics with their knowledge level and attitude. $P$-value $\leq 0.05$ was considered as statistically significant.

\section{RESULTS}

The overall response to the study was encouraging. A total of 468 healthcare workers (out of 520) filled and returned the questionnaire, giving a response rate of $90.0 \%$. The features of the study participants are shown in Table 1 . The age range of the participants was 18 to 59 years with a mean age of $31.5 \pm 4.9$ years. The majority of respondents were males $(62.4 \%)$ and belonged to the category of clinicians (35.2\%). More than half of the participants $(62.1 \%)$ knew about the SARS-CoV-2 outbreak and their main source of information was television (51.3\%). 
Table 1: The features of the study participants.

\begin{tabular}{|c|c|}
\hline Participants' features & Frequency (\%) \\
\hline \multicolumn{2}{|l|}{ Sex } \\
\hline Male & $292(62.4)$ \\
\hline Female & $176(37.6)$ \\
\hline \multicolumn{2}{|l|}{ Age (Year) } \\
\hline $18-29$ & $161(34.4)$ \\
\hline $30-39$ & $139(29.7)$ \\
\hline $40-50$ & $93(19.9)$ \\
\hline $50-59$ & $75(16)$ \\
\hline \multicolumn{2}{|l|}{ Occupation } \\
\hline Clinician & $165(35.3)$ \\
\hline Nurse & $70(15)$ \\
\hline Technician & $48(10.3)$ \\
\hline Pharmacist & $25(5.3)$ \\
\hline Other support staff & $160(34.2)$ \\
\hline
\end{tabular}

Do you know about SARS CoV-2 outbreak?

\begin{tabular}{|c|c|}
\hline Yes & $291(62.2)$ \\
\hline No & $177(37.8)$ \\
\hline \multicolumn{2}{|l|}{ Your source of information } \\
\hline Newspaper & $38(8.1)$ \\
\hline Television & $240(51.3)$ \\
\hline Social media & $129(27.6)$ \\
\hline $\begin{array}{l}\text { Websites of WHO and other } \\
\text { agencies including the ministry } \\
\text { of health } \\
\end{array}$ & $58(12.3 \%)$ \\
\hline None & $3(0.6 \%)$ \\
\hline
\end{tabular}

Participants' knowledge and attitudes towards SARS-Cov-2 are presented in Table 2. The knowledge of study participants regarding the SARSCoV-2 shows that $60.6 \%$ had sufficient knowledge while the remaining $39.4 \%$ had insufficient knowledge. Most of them knew that the current disease outbreak is caused by a virus (63.5\%). $76.5 \%$ were aware of the mode of transmission while $52.6 \%$ were familiar with the COVID-19 signs and symptoms. A high percentage of participants answered that healthcare workers (83.1\%) are more at risk of acquiring SARS-CoV-2 infection. The participants' knowledge regarding vaccination $(47.4 \%)$, the incubation period $(41.2 \%)$, and treatment by antibiotics (47.2\%) was poor (Table 2 ).

The majority $(79.7 \%)$ of the healthcare workers had a positive attitude for SARS-CoV-2 while $20.3 \%$ displayed a negative attitude. About $85.8 \%$ of respondents were aware of the prevention of SARS-CoV-2 such as isolation and other standard precautions. A majority of the participants believed that they might get the disease (82.5\%). Besides, $63.9 \%$ showed confidence in their institution to cope with the pandemic.

Table 2: Knowledge and attitude of study participants towards SARS-CoV-2.

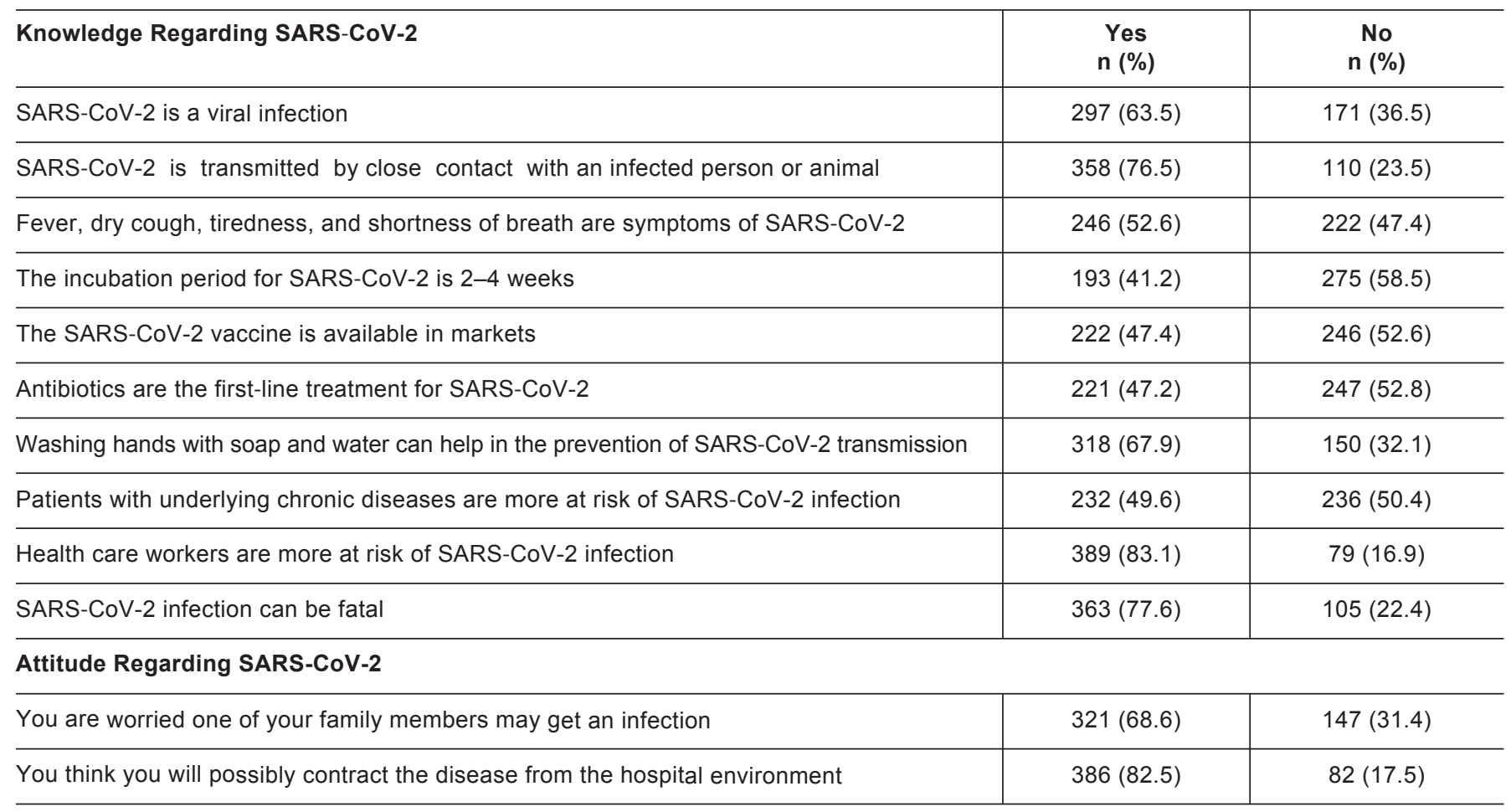




\begin{tabular}{l|c|c}
\hline Attitude Regarding SARS-CoV-2 & \multicolumn{1}{c}{$\begin{array}{c}\text { Yes } \\
\mathbf{n}(\%)\end{array}$} & $402(85.9)$ \\
\hline $\begin{array}{l}\text { Transmission of SARS-CoV-2 can be prevented by following isolation } \\
\text { and standard precautions like handwashing with soap }\end{array}$ & $64(14.1)$ \\
\hline $\begin{array}{l}\text { Prevalence of SARS-CoV-2 can be minimized by the active } \\
\text { participation of healthcare workers in hospital infection control program }\end{array}$ & $349(74.6)$ \\
\hline $\begin{array}{l}\text { If a SARS-CoV-2 vaccine was available, I would have it } \\
\text { Patients infected with SARS-CoV-2 should be kept in isolation }\end{array}$ & $440(94)$ & 119 (25.4) \\
\hline \begin{tabular}{l} 
The government hospitals are able to control the pandemic \\
\hline
\end{tabular} & $28(68.5)$ & $54(11.5)$ \\
\hline
\end{tabular}

Table 3 presents the association of participants' characteristics with the level of knowledge. Gender was significantly associated with the knowledge level $(p<0.001)$. Age was also associated with knowledge level $(p<0.001)$. Knowledge was significantly better in age groups of $40-49$ (83.8\%) and $50-59$ (81.3\%) as compared to the younger age group of $18-29$ years (38.5\%) and 30-39 years (59.7\%). Association of occupation with knowledge level was also observed $(p<0.001)$ with significantly better knowledge in clinicians $(88.4 \%)$, nurses (78\%), and pharmacists (76\%) as compared to technicians (45.8\%) and other support staff (26.3\%).

Table 3: Association of participants' features with knowledge of SARS-CoV-2.

\begin{tabular}{|c|c|c|c|}
\hline Participants' Features & $\begin{array}{c}\text { Sufficient Knowledge } \\
\text { n (\%) }\end{array}$ & $\begin{array}{c}\text { Insufficient Knowledge } \\
n(\%)\end{array}$ & P-value \\
\hline \multicolumn{4}{|l|}{ Gender } \\
\hline Female & $75(42.6)$ & $101(57.4)$ & $<0.001$ \\
\hline \multicolumn{4}{|l|}{ Age (in years) } \\
\hline $30-39$ & $83(59.7)$ & $56(40.3)$ & \multirow{3}{*}{$<0.001$} \\
\hline $40-49$ & $78(83.9)$ & $15(16.1)$ & \\
\hline $50-59$ & $61(81.3)$ & $14(18.7)$ & \\
\hline \multicolumn{4}{|l|}{ Occupation } \\
\hline Pharmacist & $19(76.0)$ & $6(24)$ & \multirow{2}{*}{$<0.001$} \\
\hline Other support staff & $42(26.3)$ & $118(73.7)$ & \\
\hline \multicolumn{4}{|c|}{ Do you know about the SARS-CoV-2 outbreak? } \\
\hline Yes & $203(69.8)$ & $88(30.2)$ & \multirow{2}{*}{$<0.001$} \\
\hline No & $81(45.8)$ & $96(54.2)$ & \\
\hline
\end{tabular}

The association of participants' features with their attitude towards SARS-COV-2 is depicted in Table 4. Age is associated with participants' attitudes regarding the COVID-19 pandemic $(p<0.001)$. The proportion was participants with a positive attitude were significantly high for age groups $40-49$ years $(89.2 \%)$ and $50-59$ years $(85.3 \%)$ as compared to the age group $30-39$ years
(67.6\%) and $18-29$ years (44.1\%). Association between occupation and attitude towards disease was also observed $(p<0.001)$. The positive attitude was more prevalent in clinicians (94.5\%), pharmacist (88\%), nurses $(84.2 \%)$, and technicians $(64.5 \%)$ as compared to technical support staff $(29.3 \%)$. 
Table 4: Association of participants' features with the attitude towards SARS-CoV-2.

\begin{tabular}{|c|c|c|c|}
\hline Participants' Features & $\begin{array}{c}\text { Positive Attitude } \\
\text { n (\%) }\end{array}$ & $\begin{array}{c}\text { Negative Attitude } \\
\mathrm{n}(\%)\end{array}$ & P-value \\
\hline \multicolumn{4}{|l|}{ Gender } \\
\hline Female & $132(75.0 \%)$ & $44(25.0 \%)$ & $<0.001$ \\
\hline \multicolumn{4}{|l|}{ Age (in years) } \\
\hline $30-39$ & $94(67.6)$ & $45(32.4)$ & \multirow{3}{*}{$<0.001$} \\
\hline $40-49$ & $83(89.2 \%)$ & $10(10.8)$ & \\
\hline $50-59$ & $64(85.3 \%)$ & $11(14.7)$ & \\
\hline \multicolumn{4}{|l|}{ Occupation } \\
\hline Clinician & $156(94.0)$ & $10(6.0)$ & \multirow{3}{*}{$<0.001$} \\
\hline Pharmacist & $22(88.0)$ & $3(12.0)$ & \\
\hline Other support staff & $47(29.4)$ & $113(70.6)$ & \\
\hline
\end{tabular}

\section{DISCUSSION}

This study was the first of its kind from the AJK region since the SARS-CoV-2 outbreak. Currently, SARS-CoV-2 is the most discussed issue around the globe, especially among patients and healthcare workers. The safety of healthcare workers is vital in case of any pandemic particularly when a country is running on limited professional manpower in the hearth sector.

Our findings showed that $60.6 \%$ of the healthcare workers had sufficient knowledge about the SARS-CoV-2 outbreak. As such, this is not very encouraging and indicated the implementation of educational and awareness programs for healthcare workers.

About $50 \%$ of our study participants reported the television and $27.6 \%$ social media as the main source of information about SARS-CoV-2. This was in line with previously published studies among healthcare workers, where social media and television were the foremost sources of information [16-20]. The use of websites from $\mathrm{WHO}$ and other agencies was mentioned by only $12.3 \%$ of the respondents. This differs from the study by Assad et al. [10] where the Ministry of Health website was the main source of information. It is pertinent to mention that the use of social media as a source of information is of concern due to the credibility and validity of the content. It is therefore very important that healthcare workers should review the educational material available on credible agencies' websites [21].

A sufficient level of knowledge was present among healthcare works regarding the preventive measures $(67.9 \%)$, causative agent $(63.4 \%)$, and the mode of transmission (76.5\%). These findings were consistent with the outcomes of previously reported studies [22-24]. Regarding the level of knowledge for disease symptoms, relatively low findings were evident $(52.6 \%)$. This was in agreement with a study by Tice et al. [25] where participants had a low level of knowledge about the symptoms of viral disease in question.

The occupation was considerably linked to the knowledge and attitude of healthcare workers. The clinicians (88.4\%) and nurses $(78.5 \%)$ showed relatively more knowledge as shown in earlier studies by Reusken et al. [26] and Alkot et al. [27]. Moreover, our findings exhibited a high level of knowledge in the pharmacists' category (76\%) as already seen in Vietnam [17]. Healthcare workers in the age category of $40-49$ years (83.9\%) showed a high level of satisfactory knowledge followed by the category of 50-59 years (81.3\%). Two previously published studies also revealed that age was significantly associated with a higher level of sufficient knowledge [19, 28].

The majority $(79.7 \%)$ of the healthcare workers in our study had a positive attitude towards SARS- CoV-2. Most of the participants $(88.5 \%)$ agreed that SARS-CoV-2 patients should be isolated and $68.6 \%$ of the participants were concerned about their family members being infected with SARS-CoV-2. These findings were consistent with those previously reported $[19,24]$. The participants supported the idea of active participation in the hospital infection control program $(74.6 \%)$ and the role of preventive measures to stop transmission (85.9\%). About $63.9 \%$ assumed the government can control the pandemic as reported in earlier studies [21, 24]. 


\section{CONCLUSION}

The outcomes of our study revealed that overall healthcare workers had an acceptable level of knowledge and a positive attitude towards the SARS-CoV-2 outbreak. However, there was a significant difference in the knowledge base of different occupations. Awareness interventions are necessary to improve the knowledge gap. Large scale studies are imperative to further study the dynamics of knowledge and attitude towards SARS-CoV-2 in the rest of the country.

\section{LIMITATIONS}

The study was conducted at a divisional level tertiary care teaching hospital and may not be generalized to the whole country. We had a limitation in the interpretation of our findings as the outbreak is ongoing and no large scale research studies available to compare.

\section{CONFLICT OF INTEREST}

The authors declare no conflict of interest.

\section{FUNDING}

None.

\section{ACKNOWLEDGEMENTS}

We wish to acknowledge the support received from Dr. Amnah Shaukat and hospital administration for data compilation.

\section{REFERENCES}

1. World Health Organization. Coronavirus disease 2019 (COVID-19) situation report. Available at: https://www.who. int/docs/default-source/coronaviruse/situationreports/20200322-sitrep-62-covid-19.pdf?sfvrsn=f7764c46_2 [Accessed on: Aug 24, 2020].

2. World Health Organization. Statement on the second meeting of the International Health Regulations (2005) Emergency Committee regarding the outbreak of novel coronavirus (2019-nCoV). Available at: https://www.who.int/news-room/ detail/30-01-2020-statement-on-the-second-meeting-of-theinternational-health-regulations-(2005)-emergencycommittee-regarding-the-outbreak-of-novel-coronavirus(2019-ncov) [Accessed on: April 24, 2020].

3. National Institute of Health, Pakistan. Daily Situation Report Pakistan COVID-19. Available at: https://www.nih.org.pk/wpcontent/uploads/2020/03/COVID-19-Daily-UpdatedSitRep-29-Mar-2020.pdf [Accessed on: Aug 24, 2020].

4. World Health Organization. Coronavirus disease (COVID-19) outbreak: rights, roles and responsibilities of health workers, including key considerations for occupational safety and health. Available at: https://www.who.int/docs/default-source/ coronaviruse/who-rights-roles-respon-hw-covid-19. pdf?sfvrsn= bcabd401_0 [Accessed on: July 28, 2020].
5. Assiri A, McGeer A, Perl TM, Price CS, Al Rabeeah AA, Cummings DA, et al. Hospital outbreak of Middle East respiratory syndrome coronavirus. N Engl J Med 2013: 369: 407-16.

6. Oboho IK, Tomczyk SM, Al-Asmari AM, Banjar AA, Al-Mugti $\mathrm{H}$, Aloraini MS, et al. 2014 MERS-CoV outbreak in Jeddah - a link to health care facilties. N Engl J Med 2015; 372: 846-54.

7. World Economic Forum. What's needed now to protect health workers: WHO COVID-19 briefing. Available at: https://www.weforum.org/agenda/2020/04/10-april-whobriefing-health-workers-covid-19-ppe-training/ [Accessed on: May 11, 2020].

8. Ran L, Chen X, Wang Y, Wu W, Zhang L, Tan X. Risk factors of healthcare workers with corona virus disease 2019; a retrospective cohort study in a designated hospital of Wuhan in China. Clin Infect Dis 2020; ciaa287. [Epub ahead of print]

9. Kim SG. Healthcare workers infected with Middle East respiratory syndrome coronavirus and infection control. J Kor Med Assoc 2015: 58: 647-54.

10. Asaad AM, El-Sokkary RH, Alzamanan MA, El-Shafei M. Knowledge and attitudes towards Middle East respiratory syndrome-coronavirus (MERS-CoV) among health care workers in south-western Saudi Arabia. East Mediterr Health J 2019. [Epub ahead of print].

11. Sameer A, Mohammad B, Mansour A, Abdulrahman A Knowledge and attitude of dental health professionals about Middle East respiratory syndrome in Saudi Arabia. J Int Soc Prev Community Dent 2018; 8: 137-144.

12. Deng JF, Olowokure B, Kaydos-Daniels SC, Chang HJ, Barwick $\mathrm{RS}$, Lee $\mathrm{ML}$, et al. Severe acute respiratory syndrome (SARS): knowledge, attitudes, practices and sources of information among physicians answering a SARS fever hotline service. Public Health 2006; 120: 15-19.

13. von Elm E, Altman DG, Egger M, Pocock SJ, Gøtzsche PC, Vandenbroucke JP STROBE Initiative. The strengthening the reporting of observational studies in epidemiology (STROBE) statement: guidelines for reporting observational studies. Lancet 2007; 370: 1453-7.

14. Centers for Disease Control and Prevention. Coronavirus Disease 2019 (COVID-19). Frequently Asked Questions. Available at: https://www.cdc.gov/coronavirus/2019-ncov/faq.html [Accessed on: May 10, 2020].

15. World Health Organization. Q\&A on coronaviruses (COVID-19). Available at: https://www.who.int/news-room/q-a-detail/q-acoronaviruses [Accessed on: May 10, 2020].

16. Huynh G, Nguyen TN, Tran VK, Vo KN, Vo VT, Pham LA. Knowledge and attitude toward COVID-19 among healthcare workers at District 2 Hospital, Ho Chi Minh City. Asian Pac J Trop Med 2020. [Epub ahead of print]

17. Al-Hazmi A, Gosadi I, Somily A, Alsubaie S, Saeed AB Knowledge, attitude and practice of secondary schools and university students toward Middle East Respiratory Syndrome epidemic in Saudi Arabia: a cross-sectional study. Saudi J Biolog Sci 2018; 25: 572-7.

18. Kim CJ, Choi WS, Jung Y, Kiem S, Seol HY, Woo HJ, et al. Surveillance of the Middle East respiratory syndrome (MERS) 
coronavirus (CoV) infection in healthcare workers after contact with confirmed MERS patients: incidence and risk factors of MERS-CoV seropositivity. Clin Microbiol Infect 2016: 22: 880-6.

19. Khan MU, Shah S, Ahmad A, Fatokun O. Knowledge and attitude of healthcare workers about Middle East Respiratory Syndrome in multispecialty hospitals of Qassim, Saudi Arabia. BMC Pub Health 2014; 14: 1281.

20. Kharma MY, Alalwani MS, Amer MF, Tarakji B, Aws G. Assessment of the awareness level of dental students toward Middle East Respiratory Syndrome-coronavirus. J Int Soc Prev Comm Dent 2015: 5: 163-9.

21. Meyer B, García-Bocanegra I, Wernery U, Wernery R, Sieberg A, Müller MA, et al. Serologic assessment of possibility for MERS-CoV infection in equids. Emerg Infect Dis 2015; 21: 181-2.

22. Almutairi KM, Al Helih EM, Moussa M, Boshaiqah AE, Saleh Alajilan A, Vinluan JM, et al. Awareness, attitudes, and practices related to coronavirus pandemic among public in Saudi Arabia. Fam Comm Health 2015: 38: 332-40.

23. Al-Hazmi A, Gosadi I, Somily A, Alsubaie S, Saeed AB Knowledge, attitude and practice of secondary schools and university students toward Middle East Respiratory Syndrome epidemic in Saudi Arabia: a cross-sectional study. Saudi J Biolog Sci 2018; 25: 572-7.

24. Al-Mohaissen M. Awareness among a Saudi Arabian university community of Middle East respiratory syndrome coronavirus following an outbreak. East Mediter Health J 2017: 23: 351-60.

25. Tice AD, Kishimoto M, Dinh CH, Lam GT, Marineau M. Knowledge of severe acute respiratory syndrome among community physicians, nurses, and emergency medical responders. Prehosp Disaster Med 2006; 21:183-9.

26. Reusken CB, Farag EA, Haagmans BL, Mohran KA, Godeke G, Raj S, et al. Occupational exposure to dromedaries and risk for MERS-CoV infection, Qatar, 2013-2014. Emerg Infect Dis 2015; 21: $1422-5$

27. Alkot M, Albouq AM, Shakuri AM, Subahi SM. Knowledge, attitude, and practice toward MERS- CoV among primary healthcare workers in Makkah Al-Mukarramah: an intervention study. Int J Med Sci Pub Health 2016: 5: 952-59.

28. Hoda J. Identification of information types and sources by the public for promoting awareness of Middle East respiratory syndrome coronavirus in Saudi Arabia. Health Educ Res 2016: 31: 12-23. 